\title{
Transitional Knowledge in the Acquisition of Concepts
}

\author{
Michelle Perry \\ University of Michigan
}

\section{R. Breckinridge Church Susan Goldin-Meadow}

The University of Chicago

\begin{abstract}
These studies explore children's conceptual knowledge as it is expressed through their verbal and gestural explanations of concepts. We build on previous work that has shown that children who produce a large proportion of gestures that do not match their verbal explanations are in transition with respect to the concept they are explaining. This gesture/speech mismatch has been called "discordance." Previous work discovered this phenomenon with respect to 5- to 7-yearold children's explanations of conservation problems. Study 1 shows: (1) that older children (10 to 11 years old) exhibit gesture/speech discordance with respect to another concept, understanding the equivalence relationship in mathematical equations, and; (2) that children who produce many discordant responses in their explanations of mathematical equivalence are more likely to benefit from instruction in the concept than are children who produce few such responses. Studies 2 and 3 explore the properties and usefulness of discordance as an index of transitional knowledge in a child's acquisition of mathematical equivalence. Under any circumstance in which new concepts are acquired, there exists a mental bridge connecting the old knowledge state to the new. The studies reported here suggest that the combination of gesture and speech may be an easily observable and significantly interpretable reflection of knowledge states, both static and in flux.
\end{abstract}

This research was supported by Grant \#RO1 HD18617 from the National Institute of Child Health and Human Development to S. Goldin-Meadow, by a grant from the Benton Foundation to the University of Chicago, and by funds from the Center for Developmental Studies at the University of Chicago. Preparation of this manuscript was conducted while R. B. Church was a Postdoctoral Fellow in the Clinical Research Training Program in Adolescence jointly sponsored by the Michael Reese Hospital and Medical Center and by the University of Chicago, and funded by an institutional training grant from the National Institute of Mental Health \#2T32MH14668-12. The authors would like to thank Ellen Eichen, Susan Levine. Lisa Liu, Rachel Mayberry, David McNeill, Bill Meadow, Carolyn Mylander. Jim Stigler. Susan Stodolsky. Sharon Syc, Tom Trabasso, and Rhonda Wodlinger-Cohen for their comments throughout the development of this project. The extensive work done by Anne Wells in collecting data for Study 2, and by Martha Wagner and Sharon Norris in coding and analyzing data for Studies 1 and 3 is greatly appreciated.

Correspondence and requests for reprints should be sent to Michelle Perry at the University of Michigan, 3402 Mason ltall, Ann Arbor. MI 48109-1027. 
One of the most elusive concepts to validate in the study of learning is the transitional knowledge state. Work by Piaget (e.g., 1967) and others (e.g., Siegler, 1979) has described the progressive levels children pass through while acquiring concepts, but relatively little work has addressed how children actually make the transition from one level of understanding to the next (see Keil, 1984; Kessen, 1962, 1984; Sternberg, 1984). The purpose of the present investigation is to identify children who are in a transitional state between levels of conceptual understanding and to explore the differences between transitional and stable knowledge states.

\section{The Transitional Knowledge State}

The notion of receptivity to environmental input has often been associated with transitional knowledge states: the hypothesis being that a child in a transitional knowledge state is one who has not yet displayed consistent knowledge of a concept but whose underlying cognitive structures are sufficiently developed to allow him to accommodate new information in that concept (cf. Beilin, 1965; Brainerd, 1972; Langer \& Strauss, 1972; Murray, 1974; Strauss \& Langer, 1970; Strauss \& Rimalt, 1974). Although the notion of a transitional knowledge state is intuitively appealing, it has proved very difficult to operationalize.

The transitional knowledge state has frequently been defined operationally as one that can be influenced by instruction (e.g., Strauss, 1972; Vygotsky, 1962). Using this definition, pinpointing the transitional state is easy in retrospect since any group of children can be exposed to instruction and the subset who benefit from the instruction will have been, by definition, in "transition." Although this post hoc definition itself lacks predictive value, it can serve as the standard against which other prospective characterizations of the transitional knowledge state are evaluated. In other words, any proposed marker of transitional knowledge ought to be able to divide children into those who are more and less ready to progress to a new level of understanding of a concept.

One variable proposed to identify the transitional knowledge state, and one that could be used predictively, is the coexistence of unintegrated levels of understanding (Beilin, 1965; Piaget, 1967; Strauss, 1972). Children who exhibit unintegrated levels of understanding of a concept by this hypothesis would be "transitional," that is, more likely to progress to a new level of understanding of that concept than children who do not exhibit unintegrated levels of understanding. However, determining whether or not a child has unintegrated knowledge has itself proved to be quite difficult (Kessen, 1984).

One technique for detecting whether a child has unintegrated levels of understanding with respect to a concept is to probe the consistency of the child's problem-solving behaviors on tasks instantiating that concept. A child who sometimes performs correctly and sometimes incorrectly on the same problem or across a set of similar problems might be thought to have knowledge of the 
correct solution that co-exists with, and is not integrated with, his incorrect knowledge (Wilkinson, 1982). For example, researchers have characterized children who conserve on some conservation tasks but not on others as having a (correct) understanding of conservation that co-exists with their (incorrect) beliefs in nonconservation (Strauss, 1972).

It will, of course, come as no surprise if it turns out that a child who is correct on a problem some (but not all) of the time is more likely to progress to a new level of understanding (i.e., is more likely to be transitional) than a child who is never correct on that problem. In addition to being somewhat obvious, characterizing the transitional knowledge state as one in which a child is sometimes correct and sometimes incorrect also appears to be overly narrow. After all, a child who produces no correct responses at all, although not as advanced as a child who is correct some of the time, might still be in a transitional knowledge state, ready to progress to a partially correct state. For example, Gelman (1969) instructed a group of 5-year-olds, all of whom failed an entire set of Piagetian conservation tasks, and found that some of the children benefitted from instruction to focus on the relevant dimensions of the conservation problems, while others did not. The children who benefitted from training could retrospectively be defined as transitional; yet there was no apparent way of determining a priori who would benefit from training, since all of the children were incorrect on all of the problems in the pretest.

A second technique commonly used to identify children in transition is to consider a child transitional if he has knowledge of the component parts of a concept but has not yet integrated those components and therefore has not yet mastered the entire concept. This technique is basic to the notion of learming "readiness." For example, children who possess all of the component skills necessary to read are said to be "reading ready" and have been shown to read earlier than children who do not possess these component skills (Wagner \& Torgesen, 1987). As a second example, Siegler (1976) showed that, although 5and 8-year-old children both failed to predict whether a balance scale would tip to the right, tip to the left, or remain centered when released, the 8-year-old children possessed the components necessary to progress to the next level of understanding of the balance scale while the 5-year-old children did not; in particular, in a separate encoding task, the 8-year-old children were able to encode both the weight and distance on the balance scale while the 5-year-old children encoded only weight. Thus, the 8-year-old children appeared to be "ready" to learn about the balance scale and, indeed, Siegler (1976) found that the 8-year-old children were able to benefit from instruction on the balance scale while the 5-year-old children were not.

The difficulty with predicting transitional status on the basis of "readiness" is that one needs to understand all of the components relevant to a task in order to be able to tap knowledge of those components in a child. Since a separate "readiness" test must be devised for each individual component of each con- 
cept, there can be no hope of a general "readiness" marker of transitional knowledge that could be used across a range of concepts.

\section{The Relationship Between Gesture and Speech as an Index of Transitional Knowledge}

Church and Goldin-Meadow (1986), in a series of studies in which children were tested in the Piagetian concept of conservation, reported a technique that identified children who were in a transitional state with respect to their understanding of conservation. Moreover, this technique, at least in principle, can be used to identify children who are transitional with respect to a wide range of concepts. The technique focuses not only on the information contained in children's verbal explanations of problem solutions (which have traditionally been taken to reflect, at least in part, the knowledge individuals use to solve problems, cf. Brainerd, 1973; Siegler, 1981), but also on an untapped behavior resource that frequently and predictably accompanies spoken explanations-gesture. McNeill (1985, 1986; McNeill \& Levy, 1982) suggests that gesture, a separate channel of communication, allows an observer to view additional aspects of mental representation that are not captured in speech.

Church and Goldin-Meadow (1986) found that, when 5- to 8-year-old children were asked to explain their solutions to a set of conservation problems, the children gestured along with their spoken explanations. Moreover, the gestures produced by the children, like their speech, conveyed information about the conservation task; specifically, about the attributes of the objects used in the conservation tasks, and about the actions performed on those objects. For example, when asked to explain his solution to a liquid quantity conservation problem, one child focused on the height of the water in both speech ("there is less water in the dish because the dish is short and the glass is tall") and in gesture (a flat hand with the palm facing down first demarcates the height of the dish and then moves to demarcate the height of the glass).

In addition, Church and Goldin-Meadow examined the relationship between gesture and speech within each explanation. They found that, for a subset of children, gestures tended to convey information different from that conveyed in the accompanying speech. Church and Goldin-Meadow defined two new terms: "discordance," which signifies that the child had produced many explanations in which gesture fails to match speech, and "concordance," which signifies that the child had produced few such mismatches. They further hypothesized that discordance was an operational index of the transitional knowledge state, and that discordant children would progress to the next level of conservation understanding before concordant children would.

In order to validate gesture/speech discordance as an index of transitional knowledge, Church and Goldin-Meadow (1986) exposed a group of partial con- 
servers (i.e., children who gave correct judgments on some but not all of a set of six conservation tasks) to instruction in conservation and evaluated their performance on a posttest. They found that those children who were discordant on the pretest (i.e., produced a large proportion of gesture/speech mismatches) were more likely to benefit from training than the children who were concordant on the pretest (i.e., produced few such mismatches). This observation held true even though both groups of partial conservers (the discordant partial conservers and the concordant partial conservers) displayed the same level of understanding of conservation on the pretest, as assessed by number of correct judgments and quality of verbal explanations. Thus, gesture/speech discordance was validated as a means of identifying children who are in a transitional knowledge state, at least with respect to conservation.

One limitation of the Church and Goldin-Meadow (1986) study is that it focused on transition with respect to only one concept-conservation. The present series of studies will attempt to deternine whether discordance can serve as a more general index of transitional knowledge by exploring gesture/speech discordance in a second concept, mathematical equivalence (understanding that quantities on both sides of a mathematical equation are equivalent). Study 1 is designed to investigate two questions: First, does gesture/speech discordance exist in a concept other than conservation? We will probe children's understanding of mathematical equivalence, and determine whether children can be identified as either concordant or discordant with respect to this concept. Second, does discordance predict transition with respect to the child's understanding of mathematical equivalence? We will determine whether children who produce discordant responses are more likely to benefit from instruction in mathematical equivalence than are children who produce concordant responses. As in our conservation study, we control for absolute level of understanding, in this case, as assessed by the number of correct solutions on a preinstruction addition test. In this way, we hope to validate discordance as an index of transitional knowledge with respect to a second concept.

The remaining two studies are designed to probe discordance itself, exploring its properties in an attempt to understand this measure better as an index of transitional knowledge. Study 2 explores whether a child can be discordant with respect to one concept (a concept he is likely to be in the process of mastering) but concordant with respect to a second concept (a concept he is likely to have already mastered). In other words, we explore whether discordance varies within the individual child according to his understanding of the concept being explained.

The discordant child, by definition, says one thing while gesturing another and thus is inconsistent across the modalities he uses to express his beliefs about a concept. Study 3 investigates whether discordant children are inconsistent even when only one modality - the verbal modality - is considered, and whether this 
verbal inconsistency is responsible for the discordant child's heightened receptivity to instruction.

\section{STUDY 1}

Study I extends previous observations of gesture/speech discordance in conservation to a new concept, mathematical equivalence. The initial goal of Study 1 was to examine whether gesture/speech discordance exists in children's explanations of this second concept. To meet this goal, we first determined whether children, asked to explain their solutions to a series of addition problems, would produce gestures along with their spoken explanations. We then determined whether the children who gestured would produce explanations in which the information conveyed in gesture failed to match the information conveyed in speech; that is, we determined whether any of the children could be considered "discordant" with respect to mathematical equivalence. The second goal of Study 1 was to examine whether gesture/speech discordance could be used to index transitional knowledge with respect to mathematical equivalence. To meet this goal, we exposed the children, later classified as either "discordant" or "concordant" on the basis of their explanations on the original addition test, to training on the addition problems, and evaluated their performance on a posttest and generalization test. Our hypothesis was that children who were discordant on the pretest would be more likely to benefit from the instruction than children who were concordant.

\section{METHOD}

\section{Choosing the Task}

We have chosen to explore gesture/speech discordance with respect to the concept of mathematical equivalence, that is, understanding that one side of an equation represents the same quantity as the other side of the equation. We have selected problems that reflect the principle of associativity over addition to instantiate one notion of mathematical equivalence. The associative principle of addition allows numbers to be grouped on one side of an equation without changing the equality relationship between the two sides of the equation. For example, ' $4+6+9=10+9$ ' makes use of the associative principle since the 4 and the 6 from the left side of the equation can be grouped and summed to produce the 10 on the right side of the equation.

We have chosen the concept of mathematical equivalence to extend our work on discordance because the concept is parallel to conservation in certain respects, yet remains sufficiently distinct to permit inferences of the generality of the discordance measure as an index of transitional knowledge. The tasks used to assess the concepts of conservation and mathematical equivalence are similar in that quantities are presented that appear different yet actually are equivalent. For 
example, six checkers in a line have the same quantity as six checkers in a circle (from a conservation task) and $4+6+9$ has the same quantity as $10+9$ (from a mathematical equivalence task). The two concepts differ, however, in several respects: age of acquisition (conservation is typically acquired around ages 5 to 8, mathematical equivalence around 9 to 12 ), level of abstraction (conservation is a concrete operational task, mathematical equivalence is a task involving manipulation of symbols), and dependence upon input (conservation is typically acquired without benefit of instruction, while mathematical equivalence will be acquired only after some instruction in the symbol system of formal mathematics, cf., Feldman, 1980; Vygotsky, 1962).

We studied children's solutions to problems of the form ' $a+b+c=$ c' because these problems have been found to provide a valid indication of children's knowledge of the equal sign (Perry, 1985). Children ages 9 to 12 are capable of solving simple addition problems of the form ' $a+b+c=\ldots$ ' and thus appear to understand the equal sign. However, these children may be getting the correct answer to these simple problems for the wrong reasons; for example, a child may interpret the equal sign as an instruction to add all of the numbers on the left side of the equation (and not as an instruction to make both sides of the equation equal, cf. Behr, Erlwanger, \& Nichols, 1980; Ginsburg, 1977; Kieran, 1980). Indeed, in a study of 227 fourth- and fifth-grade children, Perry (1985) found that $88 \%$ of the children-all of whom could perform well on simple addition problems - failed to solve more complex problems like $4+6+9=$ $+9^{\prime}$, thus appearing to have, at best, an incomplete understanding of the equal sign.

A second reason for choosing this particular form of addition problems was that most children in the targeted age range typically possess the skills that are logically prerequisite to solving problems of this type (i.e., they can add, subtract, group, etc.). Moreover, these problems are not included in most firstthrough fourth-grade math curricula (Freeman, Kuhs, Porter, Floden, Schmidt, \& Schwille, 1983; Perry, 1988). Thus, it was likely that the children had not received formal instruction in problems of this type.

The six mathematical equivalence problems that were used in this study are presented in Table 1 . As can be seen from the table, each of the numbers in the six problems is less than 10; this precaution was taken in order to reduce errors

Table 1. The 6 Addition Problems in the Paper and Pencil Test

1. $7+6+5=$

2. $3+7+9=$

3. $4+6+9=-+9$

4. $2+5+9=2+$

5. $7+4+2=7+$

6. $3+6+8=3+$ 
caused by faulty addition algorithms (e.g., "bugs" in carrying, see Brown \& Burton, 1978, which appear more frequently when children work with large numbers).

\section{Subjects}

Forty children from the fourth and fifth grades in five schools in the Chicago area participated in the paper-and-pencil addition test. Children who were successful on all or some of the six problems on the test were eliminated from the study (only 3 children in this sample). The remaining 37 children who gave incorrect solutions on all six problems comprised the subjects for the study. Our decision to include only those children who were incorrect on all six pretest problems stems from the desire to explore transitional knowledge in a group of children who did not explicitly show partial knowledge of the concept.

\section{Procedure}

Each child was tested individually and participated in a series of four consecutive videotaped sessions conducted on the same day. The sessions included pretest, training, posttest, and generalization sessions.

(1) During the pretest, each child was administered a paper-and-pencil test containing six addition problems (see Table 1). The children were told to do their best on the problems and not to worry if some of the problems were difficult. No time limit on the test was imposed but the test took no longer than 5 minutes for any of the children (mean time for completion $=2$ minutes, 9 seconds, $S D=53$ seconds). At the completion of the paper-andpencil test, each child was asked to explain how he or she arrived at his answers. The experimenter wrote the first addition problem of the test on the blackboard, including the child's answer to the problem, and asked, "Can you tell me how you figured out that answer?" After the child responded, the experimenter wrote the second problem on the blackboard and repeated the question. The experimenter continued until the child had explained the solutions to all six problems.

(2) During training, the child was exposed to instruction in the principle underlying the addition problems. We selected this type of instruction because principle-based (or goal-based) instruction has been shown to be particularly effective in extending and deepening a child's understanding of a concept (e.g., Baroody \& Ginsburg, 1986; Mayer \& Greeno, 1972). ${ }^{1}$ An

\footnotetext{
' It is quite likely that the nature of the instructional input a discordant child receives affects whether the child will improve after training. Indeed, we have found that procedural training is not effective in promoting understanding of a concept in either discordant or concordant children (Perry, Church, \& Goldin-Meadow, 1988; Perry, 1988).
} 
experimenter who was not at the pretest, and therefore was blind to the child's status as concordant or discordant, wrote on the blackboard an addition problem of the sort that was on the original paper-and-pencil test. The experimenter then told the child that the goal of the problem was to make both sides of the equation equal. No instruction was given in any procedures for achieving this goal and no solutions were provided. The experimenter then wrote a second problem on the blackboard and asked the child to attempt this problem on his or her own. The experimenter gave no feedback to the child (other than general encouragement) but would repeat the instructional phrases if the child requested assistance. The experimenter repeated this sequence with two additional problems of the same type.

(3) During the posttest, each child was given a paper-and-pencil test that contained six addition problems comparable to those on the pretest.

(4) During the generalization test, each child was asked to solve two addition problems in a new form ' $a+b+c=d+\ldots$ ' (e.g., $7+2+9=8$ $+\ldots$ ). two problems instantiating a new operation, multiplication $\mathrm{a} \times \mathrm{b}$ $\times \mathrm{c}=\mathrm{a} \times{ }^{\prime}$ ' (e.g. $2 \times 4 \times 3=2 \times \ldots$ ), and a series of three interview questions designed to determine which solutions the child would consider acceptable answers to a particular problem (e.g. " "If you were the teacher and a student put a 13 in the blank for the problem $4+6+3=$

+3 , would you tell the student that his answer was correct or incorrect? Why? How about if the student put $4+6$ in the blank?' etc.).

\section{Coding the Addition Problems on the Pretest}

The number of problems the children solved correctly on the paper-and-pencil test was recorded. Because we were interested in children who had not yet acquired mathematical equivalence, we eliminated from the study children who answered any of the six problems on the test correctly ( 3 children were eliminated, as described above).

\section{Coding Explanations on the Pretest}

Coding Speech Alone. We considered all of the responses that followed the experimenter's request for an explanation, gestured as well as spoken, to comprise a child's explanation. Coding was accomplished in three stages: (1) speech alone, (2) gesture alone, and (3) the relationship between speech and gesture. Each explanation was coded first for speech alone. With the picture turned off, one coder listened only to the audio portion of the tapes and coded the information conveyed in the children's speech independently of gesture. The children produced six different types of strategies in their spoken explanations; three equivalence explanations (describing strategies in which the sum on the right side of the equation was equal to the sum on the left side) and three nonequivalence 
explanations (describing strategies in which the sum on the right side of the equation was different from the sum on the left side; see Table 2).

The three equivalence explanations were:

1. Explanations indicating that the two numbers on the left side of the equation, which do not also appear on the right side of the equation, have been grouped and summed (i.e., the grouping strategy, see Example 1 in Table 2).

2. Explanations indicating that all of the numbers on the left side of the equation have been summed and the number that appears on both sides of the equation has been subtracted from this sum (i.e., the add-subtract strategy, see Example 2 in Table 2).

3. Explanations indicating that the numbers on the right side of the equation must sum to the same total as the numbers on the left side of the equation (i.e., the equalize strategy, see Example 3 in Table 2).

Table 2. Examples of Types of Strategies Expressed in Verbal Explanations and the Matching Gesture Accompanying those Explanations

Problem: $4+6+9=\ldots+9$

Type of Verbal

Explanation

Speech

Matching Gesture

Equivalence Explanations

Grouping

Adding-Subtracting

Equalize

" 4 plus 6 plus 9 equals 19 , so to make the other side equal 19 , you need 10 more"

\section{Nonequivalence Explanations}

Add-All

"I added 4 plus 6 plus 9 plus 9 equal 28 "

Add-to-Equal Sign "I added 4 plus 6 plus 9 equals 19"

Carry

"They don't have another 4 like that so I put the 4 over there"
Hand grabs below the 4 and 6, pause, point at blank

Point at 4, point at 6, point at 9 on the left side of the equation, pause, hand pulls down under the 9 on the right side of the equation, point at blank

Sweep across the 4,6 , and 9 on the left side of the equation, point at the equal sign, sweep across the blanik and 9 on the right side of the equation

Point at 4 , point at 6 , point at left 9 , point at right 9 , point at blank

Point at 4, point at first addition sign from left, point at 6, point at second addition sign from left, point at left 9, point at blank

Point at the 4 on the left side of the equation, point at blank 
The three noncquivalence cxplanations were:

4. Explanations indicating that all of the numbers in the problem have been summed (i.e., the add-all strategy, see Example 4 in Table 2).

5. Explanations indicating that all of the numbers up to the equal sign have been summed (i.e., the add-to-equal sign strategy, see Example 5 in Table 2).

6. Explanations indicating that one number on the left side of the equation has been carried over and placed in the blank (the carry strategy, see Example 6 in Table 2).

Spoken explanations that could not be categorized as one of these six strategies were classified as "idiosyncratic." These explanations typically included imprecise information (e.g.. "I added them"), an uninterpretable grouping of the components of the problem (e.g., "I added the 6 and the 9" for the problem in Table 2), or reference to numbers that did not appear in the problem and could not be derived by addition or subtraction from the numbers that did appear in the problem (e.g. " I added 12" for the problem in Table 2).

Coding Gesture Alone. We first established a lexicon of gestures using the information conveyed in gesture and speech in explanations produced by comparably aged children in pilot work. We employed the criteria developed in Goldin-Meadow (1979; see also Feldman, Goldin-Meadow, \& Gleitman, 1978; Goldin-Meadow \& Mylander, 1984) to isolate gestures from the flow of manual behaviors and to describe the form of those gestures. We then used three sources to help attribute meaning to each gesture.

1. We relied heavily on the form of the gesture itself; for example, a hand closing in a grabbing motion can be considered a metaphoric representation of putting together a group of numbers; we therefore tentatively assigned the meaning "group" to the hand grab form.

2. We used placement of the gesture; for example, if the hand grab was typically placed under the two numbers in the addition problem that could be grouped to solve the problem (the 4 and the 6 in the problem in Table 2), we took this as evidence that this gesture did indeed mean "group."

3. We used the speech that typically accompanied the gesture; for example, if the hand grab form typically occurred when a child said, "I grouped the 4 and the 6," this frequent pairing of gesture and speech further supported the inference of the meaning of the gesture as "group."

We found that these three sources tended to converge on a single meaning for each gesture. This iterative procedure applied to pilot data allowed the establish- 
ment of the following lexicon of gestures (described in terms of form and meaning).

1. Finger points were interpreted as referring to the elements they indicated. The children used points to indicate the numbers in the problems (interpreted as a reference to the particular number indicated), the equal sign (interpreted as "equals"), the blank (interpreted as "the answer"), and addition signs (interpreted as "add the two adjacent addends"). If the child pointed to the 4 , the addition sign, and the 6 in the problem in Table 2, the sequence would be interpreted as "add 4 and 6;" if the child pointed at an addition sign but no numbers were indicated, the sequence would also be interpreted as "add the two numbers adjacent to the addition sign."

2. Hand sweeps or hand sweeps back and forth, were interpreted as "add together all of the elements within the expanse of the sweep."

3. Hand grabs or clasps, which were typically performed at or just below two numbers, were interpreted as "group these numbers together."

4. Hand pulls or sweeps down, which were typically performed over one or more numbers, were interpreted as "subtract or take away these numbers."

This lexicon of gestures established in previous work was used to code the gestural responses found on the videotapes for this study. After a first coder had transcribed the videotapes focusing on speech alone (with the picture turned off), a second coder (with the sound turned off) transcribed the gestures on the videotapes. We found that the children combined their gestural forms into strings that conveyed the information central to each of the six spoken strategies (see Table 2). The gestures in each explanation were classified as conveying one of the six strategies displayed in Table 2 or, if no strategy was discernable, as "idiosyncratic" (i.e., children indicated elements of the problem but did not combine the elements into any of the strategies identified).

Coding the Relationship between Gesture and Speech. In the final step, the coders compared the speech code and the gesture code for each explanation to determine whether the gestured and spoken strategies matched. If the strategy conveyed in gesture was the same as the strategy conveyed in speech, then the explanation was categorized as a match (see Table 2 for examples of matched gesture-plus-speech explanations for each of the six verbal strategies). If a gesture string of the sort exemplified in Table 2 was produced with a verbal explanation that conveyed a different strategy, a gesture/speech mismatch was coded. For example, for the problem $4+6+9=$ +9 , if a child pointed at the 4 , 6 , and 9 on the left side of the equation, the 9 on the right side of the equation, and then the blank (an add-all strategy conveyed in gesture) but said "I added 4 plus 6 plus 9 equals 19" (an add-to-equal sign strategy conveyed in speech), his response would be coded as a mismatch. Responses in which one modality 
conveyed an identifiable strategy but the second modality conveyed an idiosyncratic response ( $15 \%$ of the explanations) were also considered mismatches. (There were no responses in which idiosyncratic strategies were conveyed in both modalities.) Explanations containing speech alone (33\% of all explanations) were not coded for matches or mismatches (and none of the children produced explanations containing gesture alone with no speech).

Interrater reliability was established by having additional trained coders transcribe a subset of the tapes of the testing sessions in the manner described above. Reliability was 95\% agreement $(N=37)$ between coders for coding speech alone, $87 \%(N=38)$ for coding gesture alone, and $86 \%(N=36)$ for coding the relationship between gesture and speech.

\section{Coding the Posttest and Generalization Test}

The number of correct solutions a child produced on the posttest was noted; a child was considered successful on the posttest if he was correct on at least 5 of the 6 problems. In addition, the number of correct responses a child produced on each of the 7 problems on the generalization task ( 2 addition problems in a new form, 2 multiplication problems, and 3 interview questions) was noted: a child was considered successful on the generalization test if he was correct on at least 6 of the 7 problems.

\section{RESULTS}

\section{Performance on the Pretest: Discordance in Mathematical Equivalence}

Thirty of the 37 children were found to produce gestures with at least some of their verbal explanations $2 ; 21$ children produced gestures with all six of their explanations. Gesture-plus-speech explanations were therefore quite common: On average, the children produced 4.4 out of 6 explanations (5.3 if the 7 nongesturers are excluded) containing both gesture and speech, accounting for $73 \%$ of all explanations (89\% excluding the 7 nongesturers).

Looking at the relationship between the information conveyed in gesture and in speech within an explanation, we found that $29 \%$ of the 222 explanations (40\% of the 160 explanations containing both gesture and speech) produced by all of the children were mismatches (i.e.. the strategy conveyed in gesture failed to match the strategy conveyed in speech).

We next looked at the production of mismatched explanations by individual children and found that the children varied considerably in the numbers of

\footnotetext{
2 The 7 children who did not gesture at all were, by default, classified as concordant. It is important to note, however, that if these 7 non-gesturers are eliminated from the analyses, concordant children are still less likely to benefit from instruction than discordant children (35\% vs. $62 \%$. respectively, see Table 3 ).
} 
mismatched explanations they produced, with one child producing as many as six (out of six) mismatched explanations and others producing no mismatches at all. Following Church and Goldin-Meadow (1986), we classified children as either discordant or concordant on the basis of the number of mismatched responses each child produced: Children who produced three or more (out of six) explanations in which gesture did not match speech were classified as "discordant": children who produced fewer than three mismatched explanations were classified as "concordant." Using this criterion, we found that 24 of the 37 children were concordant and 13 were discordant. The concordant children produced an average of 0.8 mismatched gesture-plus-speech explanations ( $S D$ $=.99$, range 0 to 2 ), and the discordant children produced an average of 3.8 mismatched gesture-plus-speech explanations ( $S D=.91$, range 3 to 6 ).

Despite the difference in the number of gesture-speech mismatches they produced, the concordant and discordant children were similar to one another on a number of different dimensions:

1. Age (mean age was 10 years, 1 month for the 24 concordant children and 9 years, 11 months for the 13 discordant children).

2. Sex (there were 12 girls and 12 boys in the concordant group, and 8 girls and 5 boys in the discordant group).

3. Grade (there were 11 fourth graders and 13 fifth graders in the concordant group, and 8 fourth graders and 5 fifth graders in the discordant group).

4. Ability to explain mathematical equivalence verbally (the proportion of equivalence strategies, i.e., grouping, equalize, and add-subtract, expressed in spoken explanations on the pretest was .01 [2 out of 168] for the concordant children and 0 [out of 78] for the discordant children).

5. Scores on standardized achievement tests in math (mean grade equivalent level was 4.4 for the concordant group and 3.9 for the discordant group; grade equivalent level was used to compare the children because the schools used different testing instruments).

6. We found the same proportion of concordant and discordant children in each of the five schools that participated in the study.

In general, we found that, on every background characteristic examined, concordant children did not differ from discordant children, and that the only dimension along which the two groups of children were distinct was the number of gesturespeech mismatches they produced. ${ }^{3}$

\footnotetext{
${ }^{3}$ In order to determine whether the minimal differences between the discordant and concordant children in age, grade, and math level might have accounted for the differences between the children in success after training. we did a multiple regression analysis using age, grade, math level, and discordance as variables to predict success on the posttest and the generalization test. We found that the proportion of variance explained by the combination of all four variables descreased significantly when discordance was removed from the regression, but not when each of the other three variables
} 


\section{Performance on the Posttest and Generalization Test Problems}

Table 3 presents the proportion of children classified as concordant or discordant on the pretest who improved in problem solutions after training (recall that all of the children failed on all six addition problems on the pretest). The children fell into three groups on the basis of their performance on the problems in the posttest and generalization test:

1. No success on either the posttest or the generalization test.

2. Success on the posttest (which included only addition problems) but not on the generalization test (which included multiplication problems as well).

3. Success on both the posttest and the generalization test (that is, success on both the addition and the multiplication problems). ${ }^{4}$

None of the children was successful on the generalization test without also succeeding on the addition posttest.

As can be seen in Table 3, when the instruction was effective, it resulted in success on both addition and multiplication (i.e., very few of the children succeeded on the addition posttest without also succeeding on the generalization test). The relevant result for our purposes, however, is the fact that the discordant children were more likely than the concordant children to benefit from the instruction: $62 \%$ of the 13 discordant children were successful on both the posttest and the generalization test after training, compared to only $25 \%$ of the 24 concordant children $\left(\chi^{2}(1)=4.47, p<.025\right.$, one-tailed). ${ }^{5}$

(age, grade, math level) was removed, suggesting that the discordance variable explained variance in success above and beyond the variance explained by the other three variables.

4 Recall that a child was considered successful on the posttest or the generalization test if he was correct on at least 5 of the 6 posttest problems or 6 of the 7 generalization test problems. In fact, most of the children considered successful on either test were correct on the entire posttest or generalization test: $14(82 \%)$ of the 17 children considered successful on the posttest were correct on all 6 posttest problems, and $12(85 \%)$ of the 14 children considered successful on the generalization test were correct on all 7 generalization test problems. If we were to apply a more lenient criterion for success on the generalization test, allowing a child to be considered successful if he answered any of the 7 generalization test problems correctly, the partern of results presented in Table 3 remains unchanged. Using this lenient criterion for success on the generalization test, $85 \%$ of the 13 discordant were successful after training, compared to only $33 \%$ of the 24 concordant children $\left(\chi^{2}(1)=\right.$ 3.36, $p<.05$, one-tailed, see Table 3 ).

${ }^{5}$ Note that children were classified as discordant or not, and as successful or not, based on predetermined criteria; that is, both discordance and success were considered categorical variables in our analyses. The decision to treat discordance and success as categorical was, to a certain extent, arbitrary. However, it is important to note that if discordance and success are considered continuous variables (i.e., children are classified according to the number of mismatched responses they produced on the pretest, and according to the number of problems they answered correctly on the posttest and generalization test), the results remain essentially unchanged: $33 \%$ of the variance in success measured as a continuous variable was accounted for by discordance measured as a continuous variable $(F(1,36)=4.26, p=.05)$, compared to $41 \%$ of the variance in success measured as a categorical variable accounted for by discordance measured as a categorical variable $(F(1,36)=$ $6.95, p=.01$ ). 
Table 3. Proportion of Concordant and Discordant Children Improving after Training on Addition

\begin{tabular}{|c|c|c|}
\hline $\begin{array}{l}\text { Post-Training } \\
\text { Performance }\end{array}$ & $\begin{array}{c}\text { Concordant } \\
\text { Children } \\
(n=24)\end{array}$ & $\begin{array}{c}\text { Discordan } \\
\text { Children } \\
(n=13)\end{array}$ \\
\hline $\begin{array}{l}\text { Success on posttest and } \\
\text { generalization test }\end{array}$ & .25 & $.62 *$ \\
\hline Success on posttest only & .08 & .08 \\
\hline No success on posttest & .67 & .31 \\
\hline
\end{tabular}

\section{The Effect of Training on a Child's Explanations}

Up to this point, we have examined the effect of training on the children's performance on the addition and multiplication problems in the post-training tests. We now ask whether, in addition, the training had an effect on the children's explanations of their problem solutions. To do so, we compared the explanations the children produced on the pretest and the posttest.

Coding Explanations On the Pretest and the Posttest. Each explanation was classified as a match or a mismatch as described above. In addition, we classified each gesture-plus-speech match and mismatch according to the level of explanation(s) conveyed:

1. Nonequivalence if both gesture and speech conveyed rationales at the nonequivalence level,

2. Equivalence if both gesture and speech conveyed rationales at the equivalence level,

3. Mixed if one modality conveyed a nonequivalence rationale and the other modality conveyed an equivalence rationale.

Note that, in a mismatching response, the strategy conveyed in speech, by definition, does not match the strategy conveyed in gesture; we are interested here in whether the two mismatching strategies were at the same level (nonequivalence or equivalence) or at different levels (mixed).

Children were classified into groups on the basis of the number of mismatched responses they produced (concordant or discordant) and on the basis of the level of their most frequent response (nonequivalent, equivalent, or mixed). Note that the concordant child could not be classified at the mixed level simply because, in a matching response, the strategy (and therefore the level) conveyed in speech is identical to the strategy (and level) conveyed in gesture, that is, the level cannot be mixed across the two modalities. Since, by definition, the concordant child's 
most frequent response was a matching response (or a speech alone response if the child failed to gesture on a majority of explanations), the concordant child could not have produced many responses which contained an equivalence strategy in one modality and a nonequivalence strategy in the other modality; that is. the concordant child's responses could not, on average, be at the mixed level. Thus, each child was classified into one of five categories based on that child's predominant explanation (although, in principle, a child could have produced three responses at one level and three at another, this pattern never occurred; in other words, each child in the sample did indeed have a predominant response):

1. Concordant nonequivalent (Type 1), where the child produces predominantly gesture-plus-speech matches (or speech alone responses) at the nonequivalent level.

2. Discordant nonequivalent (Type 2), where the child produces predominantly gesture-plus-speech mismatches at the nonequivalent level.

3. Discordant mixed (Type 3), where the child produces predominantly gesture-plus-speech mismatches in which nonequivalence rationales exist sideby-side with equivalence rationales.

4. Discordant equivalent (Type 4), where the child produces predominantly gesture-plus-speech mismatches at the equivalent level.

5. Concordant equivalent (Type 5), where the child produces predominantly gesture-plus-speech matches (or speech alone responses) at the equivalent level.

We arranged the five categories in the above order based on the assumption that the discordant state is a transient state, one which follows a concordant (nonunderstanding) state and precedes a concordant (understanding) state. One might therefore expect children who are acquiring mathematical equivalence to begin the process at a concordant nonequivalent state, pass through a series of discordant states differing in level of knowledge (nonequivalence, mixed nonequivalence, and equivalence, equivalence), and return eventually to a concordant state, but concordant with respect to a new level of knowledge, the equivalence level.

Pretest Explanations. We first classified children according to their predominant explanation on the pretest. These data are shown in Table 4. Not surprisingly, given that none of the children could correctly solve any of the addition problems on the paper-and-pencil pretest, all 24 of the concordant children were at the concordant nonequivalent level (Type 1) and 12 of the 13 discordant children were at the discordant nonequivalent level (Type 2). The remaining discordant child was at the mixed level (Type 3). No child on the pretest was found to be at either the discordant equivalent level (Type 4) or the concordant equivalent level (Type 5). 
Table 4. Number of Children Producing the Five Types of Explanations on the Pretest and on the Posttest"

\begin{tabular}{|c|c|c|c|c|c|}
\hline & \multicolumn{5}{|c|}{ Predominant Type of Explanation } \\
\hline & Type 1 & Type 2 & Type 3 & Type 4 & Type 5 \\
\hline & $\begin{array}{l}\text { Concordant } \\
\text { Nonequivalent }\end{array}$ & $\begin{array}{c}\text { Discordant } \\
\text { Nonequivalent }\end{array}$ & $\begin{array}{l}\text { Discordant } \\
\text { Mixed }\end{array}$ & $\begin{array}{l}\text { Discordant } \\
\text { Equivalent }\end{array}$ & $\begin{array}{c}\text { Concordant } \\
\text { Equivalent }\end{array}$ \\
\hline Pretest & 24 & 12 & 1 & 0 & 0 \\
\hline Posttest & 15 & 2 & 8 & 6 & 6 \\
\hline
\end{tabular}

"Children were categorized on the basis of their predominant type of explanation (see text).

Posttest Explanations. Our next task was to reclassify the children after instruction according to their predominant explanation on the posttest. These data are also presented in Table 4 (lower row). The most obvious change from the pretest data is that, after instruction, more children were found at the discordant mixed level (Type 3 ) and, for the first time, children could be found at the discordant equivalent (Type 4) and concordant equivalent (Type 5) levels. Before training, only 1 of the 37 children was found to produce explanations of Types 3,4 , or 5 ; after training, 20 of the 37 children were found to produce explanations of these three types.

Thus, training did alter the way in which the children explained their problem solutions on the posttest. The crucial question, however, is whether training was more likely to alter posttest explanations in discordant children than in concordant children. To address this question, we calculated the proportions of concordant and discordant children who altered their explanations on the posttest. For this analysis, we attempted to equate level of knowledge and looked only at the nonequivalent children (i.e., we included the 24 concordant nonequivalent children and the 12 discordant nonequivalent children, and omitted the 1 discordant child at the mixed level). The results are presented in Table 5. Only 1 of the 12 $(8 \%)$ children classified as discordant nonequivalent on the pretest produced the same type of explanation on the posttest as on the pretest, compared to 14 of the $24(58 \%)$ children classified as concordant nonequivalent on the pretest $\left(\chi^{2}(1)=\right.$ $8.23, p<.005$, one-tailed). Moreover, $58 \%$ ( 7 of 12) of the children who were discordant nonequivalent on the pretest produced equivalence explanations (Types 4 or 5 ) after training, compared to only $21 \%$ (5 of 24 ) of the children who were concordant nonequivalent on the pretest $\left(\chi^{2}(1)=3.52, p<.05\right.$, onetailed).

In sum, we have shown that, after training, the discordant children were not only more likely to improve on problem solutions than the concordant children, but were also more likely to alter (and, in fact, improve) their explanations than the concordant children. Predictably, we found that the children who were successful on the post-training problems were the same children who produced 
Table 5. Proportion of Children Who Were Concordant or Discordant Nonequivalent on the Pretest Classified According to Their Predominant Type of Explanation on the Posttest

Predominant Type of Explanation on the Posttest

\begin{tabular}{|c|c|c|c|c|c|}
\hline & Type 1 & Type 2 & Type 3 & Type 4 & Type 5 \\
\hline Pretest Status: & $\begin{array}{c}\text { Concordant } \\
\text { Nonequivalent }\end{array}$ & $\begin{array}{c}\text { Discordant } \\
\text { Nonequivalent }\end{array}$ & $\begin{array}{l}\text { Discordant } \\
\text { Mixed }\end{array}$ & $\begin{array}{l}\text { Discordant } \\
\text { Equivalent }\end{array}$ & $\begin{array}{c}\text { Concordant } \\
\text { Equivalent }\end{array}$ \\
\hline
\end{tabular}

Type 1

Concordan $.58 \mathrm{n}$

.04

.17

1.3

.08

Nonequivalent

$(N=24)$

Type 2

Discordant

Nonequivalent

$(N=12)$

aPretest status was determined by the child's predominant type of explanation on the pretest: concordant nonequivalent (Type 1) or discordant nonequivalent (Type 2). The one child who produced predominantly discordant mixed explanations (Type 3) on the pretest was not included in this analysis.

"These proportions represent the proportions of concordant nonequivalent children and discordant children who did wot alter their explanations after training. i.e.. the proportions of children who produced the same predominant explanation on both the pretest and the posttest.

posttest explanations with equivalence in gesture and/or speech (i.e., explanations of Types 3.4, or 5; see Table 6). It is not particularly surprising that the children should begin to produce equivalence strategies in speech after training since the instruction itself contained a verbal equivalence explanation (an abbreviated version of the equalize strategy). However, since the trainer was careful to gesture during the instruction only in a stylized fashion that did not reflect any particular strategy (videotapes taken of the training session confirmed that she did indeed gesture in this fashion to all subjects), the children received no model of a gestured equivalence strategy. Nevertheless, 17 of the 20 children who produced explanations of Types 3,4, or 5 after training produced equivalence strategies in gesture (and only 6 of these children had produced equivalence strategies in gesture before training). Thus, the children had not just mimicked a verbal equivalence explanation provided by the experimenter, but had created new gestured explanations at the equivalence level.

\section{Is the Discordant Child More Knowledgeable than the Concordant Child?}

Discordant children, by definition, produce two different strategies for the same problem and, in this sense, "know more" or at least express more about a single problem than concordant children. The question we now ask is whether discor- 
Table 6. Relationship between Explanations and Success on Problems after Training:

\begin{tabular}{|c|c|c|c|c|c|}
\hline \multirow{3}{*}{$\begin{array}{c}\text { Performance on } \\
\text { Problems after } \\
\text { Training } \\
\end{array}$} & \multicolumn{5}{|c|}{ Predominant Type of Explanation on the Posttest } \\
\hline & Type 1 & Type 2 & Type 3 & Type 4 & Type 5 \\
\hline & $\begin{array}{c}\text { Concordant } \\
\text { Nonequivalent }\end{array}$ & $\begin{array}{c}\text { Discordant } \\
\text { Nonequivalent }\end{array}$ & $\begin{array}{c}\text { Discordant } \\
\text { Mixed }\end{array}$ & $\begin{array}{l}\text { Discordant } \\
\text { Equivalent }\end{array}$ & $\begin{array}{l}\text { Concordant } \\
\text { Equivalent }\end{array}$ \\
\hline No success & 14 & 2 & 4 & & \\
\hline $\begin{array}{l}\text { Success on post- } \\
\text { test only }\end{array}$ & 1 & & 1 & 1 & \\
\hline $\begin{array}{l}\text { Success on post- } \\
\text { test and gen- } \\
\text { eralization }\end{array}$ & & & 3 & 5 & 6 \\
\hline
\end{tabular}

"Number of children classified according to (1) performance on the post-training addition and multiplication problems and (2) predominant type ol explanation after tratining.

dant children are, in fact, more knowledgeable about equivalence in mathematical problems than concordant children when we look, not at their responses to a single problem, but at their responses across the set of six problems. In other words, we ask whether discordant children have more strategies in their repertoires overall than concordant children. A difference of this sort might explain why the discordant children are more likely to benefit from instruction than the concordant children.

To investigate this question, we examined pretest performances and again equated for level of knowledge, including only the nonequivalent children in our analyses (i.e., we eliminated the one discordant child at the mixed level who, by definition, produced a larger proportion of equivalence responses than the nonequivalent children). We calculated the mean number of nonequivalence and equivalence strategies produced by the 24 concordant nonequivalent children and the 12 discordant nonequivalent children before training (i.e., on the pretest). A child was given credit for a particular strategy if he produced that strategy at least once in gesture or in speech in any of his six explanations. The maximum number of different strategies a child could produce was three for the nonequivalence strategies (add-all, add-to-equal sign, carry) and three for the equivalence strategies (grouping, add-subtract, equalize). The data are presented in Table 7. Although the discordant children produced slightly more types of strategies on average than the concordant children, this difference was not reliable for either the nonequivalence strategies $(t(34)=1.28$, n.s.) or the equivalence strategies $(t(34)=1.77$, n.s.). These data suggest that the number of strategies available to the discordant children was comparable to the number available to the concordant children.

The feature that distinguishes discordant children from concordant children 
Table 7. Mean Number of Types of Strategies Produced in Gesture and/or in Speech Across the Six Explanations on the Pretest

\begin{tabular}{lcc}
\hline & $\begin{array}{c}\text { Concordant } \\
\text { Nonequivalent } \\
\text { Children } \\
(N=24)\end{array}$ & $\begin{array}{c}\text { Discordant } \\
\text { Nonequivalent } \\
\text { Children } \\
(N=12)\end{array}$ \\
\hline $\begin{array}{c}\text { Nonequivalence strategies } \\
\text { (out of 3) }\end{array}$ & 1.50 & 1.75 \\
$\begin{array}{c}\text { Equivalence strategies } \\
\text { (out of 3) }\end{array}$ & .21 & .58 \\
\hline
\end{tabular}

thus does not appear to be the types of strategies the children know, but rather the ability to produce those strategies as explanations for the same problem. Producing two strategies to explain a single problem may allow the discordant child to consider the relationship more easily (and the potential conflict) between those strategies. For example, consider a child who produces an add-all strategy in gesture and an add-to-equal sign strategy in speech. These two strategies lead to incompatible solutions to the addition problems (the add-all strategy applied to the following problem, $4+6+9=\ldots+9$, gives the sum 28 , while the addto-equal sign strategy gives the sum 19). The conflict between these two strategies may be more apparent when seen side-by-side across two modalities, and an awareness of this conflict may play a role in pushing the child toward an understanding of equivalence.

Whether or not the child is able to make use of the two pieces of information he expresses simultaneously, our data suggest that the discordant nonequivalent child differs from the concordant nonequivalent child, not in terms of how much he knows about equivalence. but in terms of the amount of information he can communicate at one time with respect to a particular equivalence problem. These findings suggest that the discordant child may have a relatively large information-processing capacity with respect to the particular problem on which he is discordant, a capacity that allows him to take in and profit from information relevant to that problem.

\section{The Modality of Expression: Does Equivalence Appear in Gesture before Speech?}

The final issue we considered is how the concordant and discordant children used the two different modalities to express their strategies. That is, we ask whether certain strategies are more likely to appear in gesture, in speech, or in both modalities. We included in this analysis the pretest explanations of the 12 discordant nonequivalent children and the 17 concordant nonequivalent children who produced gestures along with their spoken explanations (i.e., we excluded the 7 
concordant children who produced no gestures at all)." We classified the children into three groups according to the modality they used to express their nonequivalence strategies and their equivalence strategies:

1. Children who produced at least one nonequivalence (or equivalence) strategy in both gesture and speech: a child did not have to produce the strategy simultaneously in gesture and in speech to be included in this category, but merely had to produce the strategy in gesture and the same strategy in speech sometime across the set of six explanations.

2. Children who produced at least one nonequivalence (or equivalence) strategy in speech but did not produce that strategy at any time across the six explanations in gesture.

3. Children who produced at least one nonequivalence (or equivalence) strategy in gesture but did not produce that strategy at any time across the six explanations in speech.

Table 8 presents the proportion of concordant and discordant children who expressed nonequivalence and equivalence strategies in both gesture and speech, in speech but not gesture, or in gesture but not speech. Note that almost all of the children produced nonequivalence strategies in both gesture and in speech. In contrast, none of the children produced the more advanced equivalence strategies in both modalities. The concordant and discordant children did differ, however, in the modality in which equivalence appeared. The concordant children were equally likely to produce equivalence in speech or gesture: 2 concordant children $(12 \%)$ produced an equivalence strategy in speech but not gesture, and $3(18 \%)$ produced an equivalence strategy in gesture but not speech. In contrast, all 7 of the discordant children (58\%) who produced an equivalence strategy produced that strategy in gesture but not speech. Overall, the discordant children were more likely than the concordant children to produce an equivalence strategy in gesture but not speech ( 7 of the 12 discordant children vs. 3 of the 17 concordant children, $p=.027$. Fisher Exact Test). These data suggest that, at least for the discordant children, when equivalence first appears in a child's repertoire, it tends to appear in gesture and not in speech.

\section{Summary}

We have shown that, when asked to explain their solutions to problems in mathematical equivalence, a subset of children who had not yet acquired the concept produced a large proportion of explanations in which the information conveyed in gesture did not match the information conveyed in speech. Thus,

\footnotetext{
- All of the 7 concordant children who did not gesture produced only nonequivalence strategies in speech; none of these children produced equivalence stralegies.
} 
Table 8. Proportion of Children Classified According to the Modality Used to Express Nonequivalence and Equivalence Strategies on the Pretest

\begin{tabular}{|c|c|c|c|c|c|c|}
\hline & \multicolumn{3}{|c|}{$\begin{array}{c}\text { Nonequivalence Strategies } \\
\text { Expressed in }\end{array}$} & \multicolumn{3}{|c|}{$\begin{array}{c}\text { Equivalence Strategies } \\
\text { Expressed in }\end{array}$} \\
\hline & $\begin{array}{l}\text { Gesture } \\
\text { and } \\
\text { Speech }\end{array}$ & $\begin{array}{l}\text { Speech } \\
\text { but not } \\
\text { Gesture }\end{array}$ & $\begin{array}{l}\text { Gesture } \\
\text { but not } \\
\text { Speech }\end{array}$ & $\begin{array}{c}\text { Gesture } \\
\text { and } \\
\text { Speech }\end{array}$ & $\begin{array}{l}\text { Speech } \\
\text { but not } \\
\text { Gesture }\end{array}$ & $\begin{array}{l}\text { Gesture } \\
\text { but not } \\
\text { Speech }\end{array}$ \\
\hline $\begin{array}{c}\text { Concordant nonequivalent } \\
\text { children }(N=17)^{4}\end{array}$ & .88 & .12 & .00 & .00 & .12 & .18 \\
\hline $\begin{array}{l}\text { Discordant nonequivalent } \\
\text { children }(N=12)\end{array}$ & 1.00 & .00 & .00 & .00 & .00 & .58 \\
\hline
\end{tabular}

"7 of the 24 concordant nonequivalent children did not gesture at all on the pretest. These 7 children are not included in this analysis.

discordance was found in a second concept (the first being conservation, see Church \& Goldin-Meadow, 1986), a finding which suggests that discordance may be a general cognitive phenomenon and is not tied to any particular concept, age, or developmental stage.

Moreover, we found that, within a group of children who had not yet acquired mathematical equivalence (as reflected in the absence of correct solutions on the paper-and-pencil pretest), the subset of children who produced a large proportion of gesture/speech mismatches on the pretest (i.e., the discordant children) were more likely to benefit from instruction than the subset of children who produced few such mismatches (i.e., the concordant children). These data suggest that gesture/speech discordance can be used as a general marker of transitional knowledge, one that can potentially be used with a wide range of concepts.

\section{STUDY 2}

It is our hypothesis that an individual who is grappling with a particular concept, possessing an unstable and still-forming understanding of that concept, will produce gesture/speech mismatches when explaining that concept. Under this hypothesis, a child would produce mismatched responses for a concept he is in the process of mastering but not for a concept he has either mastered or has not yet begun to tackle. To investigate whether the discordant state is indeed concept-specific, fourth-grade students (i.e., 9- and 10-year-olds) were tested on two tasks: mathematical equivalence and conservation. Our goal was to determine how the same children would perform in terms of stability of understanding (i.e., discordance and concordance) on a task tapping a concept they were likely to be in the process of mastering (i.e., mathematical equivalence) versus a task tapping a concept they were likely to have already mastered (i.e., conservation). 


\section{METHOD}

\section{Subjects}

Twenty-four children from the fourth and fifth grades of a Chicago Public School participated in the paper-and-pencil addition test. These children represent a different sample from the children who participated in Study 1. The children ranged in age from $9 ; 2$ to $10 ; 6$ (mean age $9 ; 9$ ).

\section{Procedure}

Each child was tested individually and particiated first in a series of 6 Piagetian conservation tasks: 2 liquid, 2 length, and 2 number tasks (see Church \& GoldinMeadow, 1986, for the details of the tasks). For each conservation task, the child was asked to judge whether a quantity was the "same" or "different" after a transformation altering the appearance but not the quantity, and to explain each judgment.

After participating in the conservation tasks, the child was then administered a paper-and-pencil test containing the six addition problems used in Study 1 (see Table 1). As in Study 1, after the child had solved the problems, an experimenter went to the blackboard with the child, wrote the first problem (including the child's solution) on the board, and asked the child, "Can you tell me how you figured out that answer?" The experimenter continued until the child had explained the solutions to all six problems. Children's explanations of their answers to both the conservation and the mathematical equivalence tasks were videotaped.

\section{Coding}

Coding the Conservation Judgments. The conservation task was coded first for judgments and then for explanations. Children who produced a "same" judgment on all six of the conservation tasks were classifed as conscrvers. Children who produced a "same" judgment on some of the six conservation tasks and a "different" judgment on other tasks were classified as partial conservers. Children who produced "different" judgments on all six tasks were classified as nonconservers.

Coding the Conservation Explanations. Coding was accomplished in three steps: (1) speech was coded alone, (2) gesture was coded alone, and (3) the relationship between speech and gesture was coded. Each explanation was coded first for speech alone. With the picture turned off, one coder listened only to the audio portion of the tapes and coded the information conveyed in the children's speech independently of gesture. Spoken explanations were classified into three types: equivalence, nonequivalence, and noncomparative. Equivalence explanations focused on the equivalence between the object's transformed and original 
states (c.g., "the dish is short but it's wide," or "you could pour the water back into the glass"). Nonequivalence explanations focused on the nonequivalence between the object's two states (e.g., "you poured the water into the dish," or "the dish is short and the glass is tall"). Noncomparative explanations failed to focus on a comparison at all (e.g., "that's a dish," or "the dish is short;" see Church \& Goldin-Meadow, 1986, for further details and examples of these coding categories).

A second coder then viewed the videotapes, this time with the sound turned off, and coded the information conveyed in the children's gestures. Gestured explanations could also be classified into the same three categories: equivalence (e.g., a pouring motion from the dish to the glass, indicating how the original transformation could be reversed), nonequivalence (e.g., a flat palm held first at the height of the water in the dish and then at the height of the water in the glass, thereby focusing on a dimension where the two objects differed) and noncomparative (e.g., a flat palm indicating only the height of the water in the dish).

In the final step, the coders compared the speech code and the gesture code for each explanation to determine whether that explanation was a match or a mismatch. An explanation was categorized as a match if gesture expressed the same or a subset of the information that was expressed in speech (e.g., a description of reversing the pouring action in the water task, "If you poured the water back," said while gesturing the same information, a pouring motion from the dish to the glass). An explanation was categorized as a mismatch if gesture expressed different or additional information from that expressed in speech (e.g., a verbal description of the action performed on the objects, "You poured water from the glass into the dish," said while gesturing information about one of the dimensions of the objects, a flat palm demarcating first the height of the water in the glass and then the height of the water in the dish). Explanations containing speech alone were not coded for matches or mismatches (and none of the children produced explanations containing gesture alone with no speech).

Interrater reliability was established by having additional trained coders transcribe a subset of the tapes of the testing sessions in the manner described above. Reliability was $88 \%(n=36)$ agreement between coders for coding speech alone, $88 \%(n=34)$ for coding gesture alone, and $97 \%(n=35)$ for coding the relationship between gesture and speech.

Coding the Mathematical Equivalence Paper-and-Pencil Addition Test.

The number of problems the children solved correctly on the paper-and-pencil test was recorded.

Coding the Mathematical Equivalence Explanations. Explanations were coded for speech alone, gesture alone, and the relationship between gesture and speech, as described in Study 1. 


\section{Results}

Discordance in Mathematical Equivalence. Fourteen of the 24 children $(58 \%)$ were incorrect on all six problems on the paper-and-pencil addition test. Eight $(33 \%)$ were correct on some of the problems, and $2(8 \%)$ were correct on all of the problems. Thus, most of the children had not yet acquired mathematical equivalence. ${ }^{7}$

In terms of the explanations produced to justify their problem solutions, 21 of the 24 children were found to produce gestures with at least some of their verbal explanations; 13 of the 24 children produced gestures with all six of their explanations. On average, the children produced 4.1 (out of 6) explanations containing both gesture and speech. Overall, 49 of the 99 explanations (49\%) containing both gesture and speech were coded as mismatches. There was a wide range of mismatched explanations produced by the children, ranging from 0 to 6 (out of 6) per child. Children were classified as "discordant" with respect to mathematical equivalence if they produced three or more explanations (out of six) in which gesture did not match speech, or as "concordant" if they produced fewer than three such mismatches.

Using this criterion, 9 of the 24 children (38\%) were found to be discordant with respect to mathematical equivalence-approximately the same proportion of children found to be discordant with respect to mathematical equivalence in Study 1 (i.e., 13 of the 37 children, 35\%). Mean age was 9;11 for the discordant children and 9;9 for the concordant children. The mean number of mismatched explanations was 4.44 ( $S D=1.33$, range from 3 to 6 ) for the discordant children and $.60(S D=.74$, range from 0 to 2$)$ for the concordant children.

Discordance in Conservation. All 24 of the children produced at least one "same" judgment on the six conservation tasks (i.e., none of the children were nonconservers). Fourteen of the 24 children (58\%) produced "same" judgments on all six tasks (i.e., they were full conservers), and the remaining 10 children $(41 \%)$ produced "same" judgments on some of the six tasks (i.e., they were partial conservers).

In terms of the explanations produced to justify their judgments, all 24 of the children produced gestures with at least some of their verbal explanations of conservation. On average, the children produced 4.6 (out of 6) explanations containing both gesture and speech. Overall, 32 of the 110 explanations $(29 \%)$ containing both gesture and speech were coded as mismatched explanations.

\footnotetext{
${ }^{7}$ Note that the percentage of children who were successful on some or all of the six addition problems was considerably higher in Study $2(41 \%, 10$ out of 24$)$ than tt was on the pretest in Study 1 $(8 \%, 3$ out of 40 ). The public school that the children in Study 2 attended (which was within a university community) had a somewhat more advanced math curriculum than the other schools in our sample, a difference which may have contributed to the Study 2 children's relatively good performance on our addition test.
} 
There was a range of mismatched explanations produced by the children, from 0 to 4 (out of 6) per child. Children were classified as "discordant" with respect to conservation if they produced three or more explanations (out of six) in which gesture did not match speech, or as "concordant" if they produced fewer than three such mismatches.

Only 4 of the 24 children ( $17 \%$ ) were found to be discordant with respect to conservation. The small number of discordant children is predictable given that the children ranged in age from 9 to 11 years and therefore already knew a great deal about conservation (as reflected in their "same" judgments). In our previous studies of conservation in 5-to 8-year-old children who were in the process of acquiring conservation, we found that as many as $46 \%$ of these younger children $(N=80)$ were discordant on these same conservation tasks (see Studies 1 and 2 in Church \& Goldin-Meadow, 1986). Mean age was 9;10 for the 4 discordant children and 9;9 for the 21 concordant children in this study. The mean number of mismatched explanations was $3.25(S D=.50$, range from 3 to 4 ) for the discordant children and $.95(S D=.83$, range from 0 to 2 ) for the concordant children.

Discordance in Two Concepts. To determine whether a child could be discordant on one of the two concepts but concordant on the other, the children were classified according to their discordance status on both concepts. Of the 9 children who were discordant on mathematical equivalence, 3 were discordant on conservation as well, while 6 of those 9 were discordant on mathematical equivalence but concordant on conservation. In addition, one child was concordant on mathematical equivalence but discordant on conservation. The remaining 14 children in the study were concordant on both concepts. Thus, almost a third of the 24 children in this sample were discordant on one concept but concordant on the other. These data are displayed in Table 9.

Types of Gesture-Plus-Speech Explanations in the Two Concepts. We also classified the children according to the type of predominant gesture-plus-speech explanation they produced on each of the two tasks, as described in Study 1 . Since, as a group, the children had less knowledge of mathematical equivalence

Table 9. Proportion of Children who were Concordant or Discordant with Respect to Mathematical Equivalence and Conservation

\begin{tabular}{lll}
\hline & $\begin{array}{c}\text { Concordant on } \\
\text { Mathematical } \\
\text { Equivalence }\end{array}$ & $\begin{array}{c}\text { Discordant on } \\
\text { Mathematical } \\
\text { Equivalence }\end{array}$ \\
\hline Concordant on conservation & $.58(N=14)$ & $.25(N=6)$ \\
Discordant on conservation & $.04(N=1)$ & $.13(N=3)$ \\
\hline
\end{tabular}


than of conservation, we might expect that the children would produce explanations at a lower level for mathematical equivalence than for conservation. Figure 1 presents the number of children classified according to the predominant type of gesture-plus-speech explanation they produced on the mathematical equivalence task and on the conservation task. Note that, when the children were concordant with respect to mathematical equivalence, they tended to be concordant at the nonequivalent level, that is, they tended to produce predominantly Type 1 explanations. In contrast, when the children were concordant with respect to conservation, they tended to be concordant at the equivalent level, that is, they tended to produce predominantly Type 5 responses. Thus, the children tended to produce different types of gesture-plus-speech responses for a concept, depending upon their level of mastery of that concept.

Further evidence that gesture-plus-speech explanations reflect a child's level of mastery of a given concept comes from an analysis of the relationship between the children's explanations and their performance on the paper-and-pencil math test, or their performance on the same/different conservation judgments. Figure 2 presents the proportion of children characterized by predominant type of explanation, classified according to their performance on the paper-and-pencil test for mathematical equivalence (none correct, some correct, all correct) or according to their performance on the same/different judgments for conservation (some "same" judgments, all six "same" judgments; recall that all of the children produced at least one "same" judgment). Note that the children who were incorrect on all six math problems were the only children to produce predominantly Type 1 explanations, while the children who were correct on all of the problems produced predominantly Type 4 and 5 explanations. Similarly with respect to conservation, it was only the partial conservers who produced predominantly Type 1 explanations, while the full conservers produced predominantly Type 5 explanations.

In sum, discordance does not appear to be a communicative style that inevitably characterizes a child's explanations regardless of the concept that he or she is explaining. Rather, discordance appears to vary within the individual according to his understanding of the concept being explained. Thus, the data from this study are consistent with the hypothesis that discordance reflects the stability and level of a child's understanding of a particular concept.

\section{STUDY 3}

The discordant child, by definition, says one thing while gesturing another and thus is inconsistent across the modalities he uses to express his beliefs about a concept. It is possible, however, that discordant children are inconsistent even when we consider only one modality, the verbal modality, and that it is this verbal inconsistency which is responsible for the discordant child's heightened receptivity to instruction. In our previous work, we found that children who were 

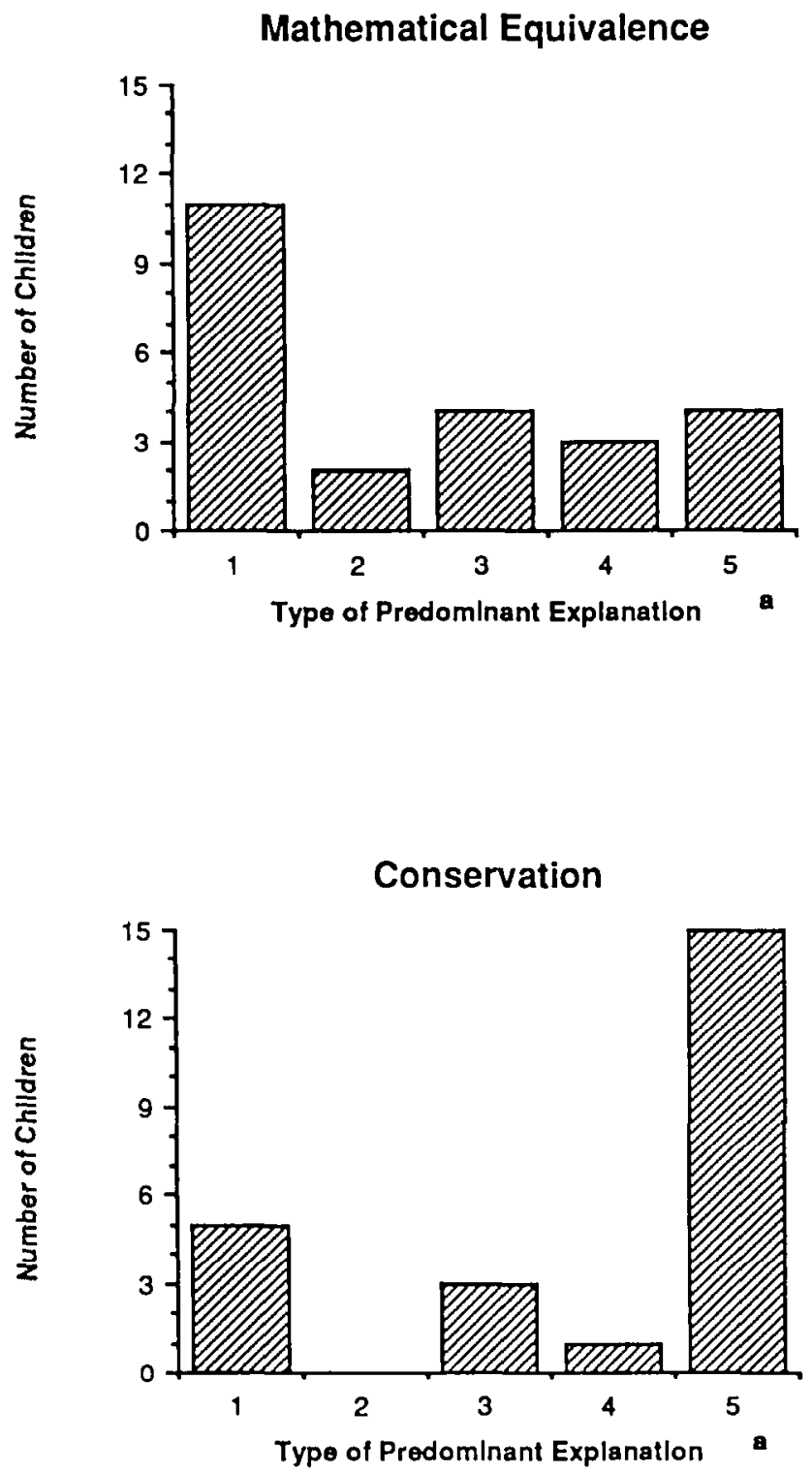

"Type $1=$ concordant nonequivalent; Type $2=$ discordant nonequivalent; Type $3=$ discordant mixed; Type 4 = discordant equivalent; Type $5=$ concordant equivalent

Figure 1. Type of predominant explanation used by the 24 children in Study 2 on the mathematical equivalence task and the conservation task. 


\section{A. Mathemalleal Equivalence}
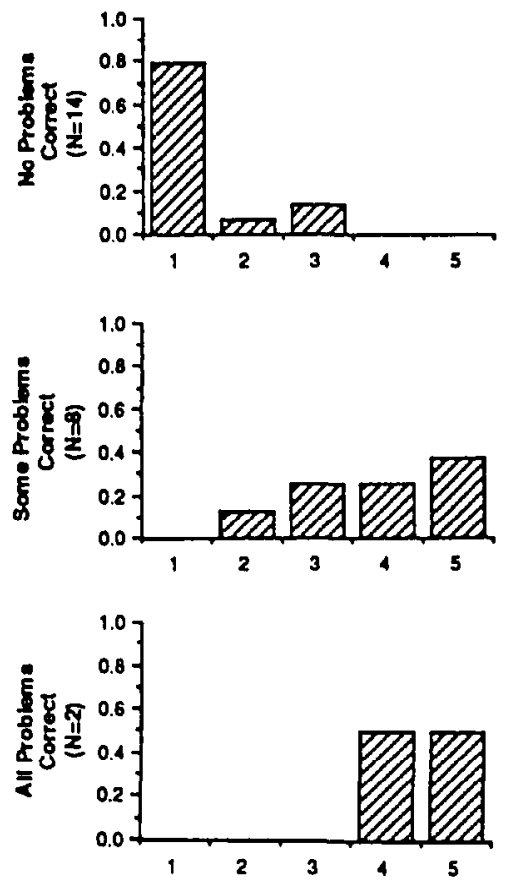

B. Concervation
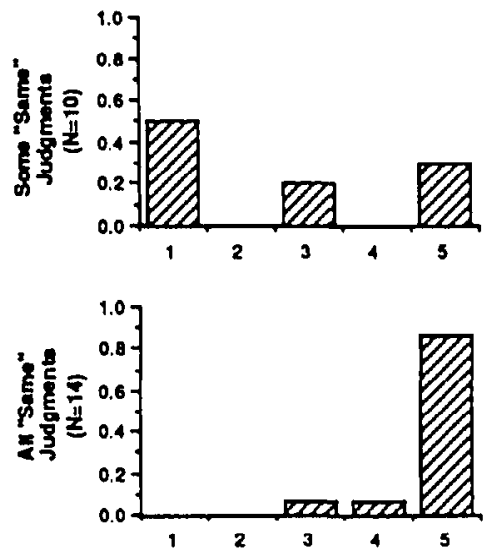

Type of Prodominant Explanation *

- Typ 1 - oonoordent nonequlvalent; Type 2 - dleoordent nonequlvalent; Type 3 - deoordent mixed; Type 4 . dieoordant nonequivatont: Trpe 6 - deneordant equivalent

Figure 2. Type of predominant explanation used by children who were correct on none, some, or all of the 6 test problems (i.e., the 6 addition problems on the mathematical equivalence task, and the 6 judgment problems on the conservation task). 
discordant with respect to conservation also tended to be inconsistent in their verbal explanations of the concept (Church \& Goldin-Meadow, 1986). In this study, we investigate whether children who are discordant with respect to mathematical equivalence will also be inconsistent in their verbal explanations of this concept. In addition, we determine whether the discordance measure is, in fact, a better predictor of success after training than verbal measures of inconsistency.

\section{METHOD}

\section{Subjects and Procedure}

Fifty-nine children, ages 9 to 12, from private Catholic schools in the Chicago area participated in the paper-and-pencil addition test described in Study 1 (Table 1). Children who were successful on all or some of the six problems on the test were eliminated from the study ( 7 children in the sample). The remaining 52 children who gave incorrect solutions on all six of the problems comprised the subjects for the study. None of these children participated in either Study 1 or Study 2.

After the child attempted to solve the problems, an experimenter went to the blackboard with the child, wrote the first problem (including the child's solution) on the board, and asked the child, "Can you tell me how you figured out that answer?" The experimenter continued until the child had explained the solutions to all six problems. The child's responses were videotaped.

\section{Coding the Paper-and-Pencil Addition Test}

The number of problems answered correctly on the paper-and-pencil test was tabulated for each child. (As described above, the 7 children who solved some or all of the six problems correctly were eliminated from the study.) In addition, the particular solution for each problem was recorded in order to compare the consistency between a child's solution to a problem and his explanation of that solution.

\section{Coding Explanations}

Explanations were coded for speech alone, gesture alone, and the relationship between gesture and speech as in Study 1. Children were classified as "discordant" if they produced three or more explanations (out of six) in which gesture did not match speech, or as "concordant" if they produced fewer than three such explanations.

\section{RESULTS}

\section{Explanations Expressed in Speech}

Each of the 52 children produced verbal explanations for all six of their (incorrect) solutions to the problems on the paper-and-pencil test. Overall, only three 
of these 312 verbal explanations exemplified a strategy that could lead to a correct solution, that is, the equivalence strategies of grouping ( $1 \%)$ and equalize ( $1 \%)$; there were no instances of the add-subtract equivalence strategy. $81 \%$ of the explanations exemplified strategies leading to incorrect solutions, that is, the nonequivalence strategies of add-all $(57 \%)$, add-to-equal sign (19\%), and carry $(5 \%)$. The children produced idiosyncratic responses in $15 \%$ of their verbal explanations, and $2 \%$ of the responses were missing because the children spoke too softly for their verbal responses to be transcribed and coded.

\section{Explanations Expressed in Gesture}

Of the 52 children, $90 \%$ also produced gestured explanations, primarily in the form of points, with some or all of their verbal explanations. As in the verbal explanations, few of the gestured explanations conveyed equivalence information. The children produced 6 instances of grouping ( $3 \%$ of the 239 total gestured explanations), 17 instances of equalize $(7 \%)$ and 4 instances of add-subtract ( $1 \%)$. In addition, $72 \%$ of the gestured explanations exemplified strategies leading to incorrect solutions, that is, the nonequivalence strategies of add-all $(45 \%)$, add-to-equal sign (24\%), and carry (3\%). The children produced idiosyncratic responses in $14 \%$ of their gestured explanations, and $2 \%$ of the responses were missed because the camera was positioned in such a way that the gestures were not visible.

Note that, although small, the incidence of gestured explanations expressing equivalence ( $11 \%$ of 239 ) was larger than the incidence of verbal explanations expressing equivalence ( $2 \%$ of $312 ; t(311)=4.76, p<.001)$. Similarly, in an analysis by child, the number of children who produced equivalence explanations in gesture (20 out of 52) was found to be larger than the number who produced equivalence explanations in speech ( 3 out of $52 ; t(50)=4.98, p$ $<.001$ ). Moreover, the 3 children who produced equivalence explanations in speech were found to produce equivalence explanations in gesture as well. These data provide further evidence for the hypothesis that equivalence appears in a child's gestures before it appears in his speech (see Study 1).

\section{The Relationship between Gesture and Speech}

Overall, the children produced an average of 4.6 (out of 6) explanations containing both gesture and speech, accounting for $77 \%$ of all explanations. Thirty-three percent of the 312 total explanations (44\% of the 239 explanations with both gesture and speech) produced by all of the children were mismatched explanations.

On the basis of the number of gesture/speech mismatches produced in their explanations, 20 of the 52 children were found to be discordant, and 32 were found to be concordant with respect to the concept of mathematical equivalence. The mean age for both the discordant and concordant children was 10;2. The discordant children produced an average of 3.95 mismatched explanations $(S D=$ 
1.09, range 3 to 6 ) and the concordant children produced an average of 0.81 mismatched explanations ( $S D=.90$, range 0 to 2 ). By design, none of the children, concordant or discordant, solved any of the six addition problems on the paper-and-pencil test correctly (i.e., the 7 children who solved some of the problems correctly were eliminated from the study, allowing us to investigate children who displayed equal understanding of the mathematical problems).

\section{Discordance and Inconsistency}

Following our work on conservation (see Church \& Goldin-Meadow, 1986), we established two verbal measures of consistency of explanation-measures that were completely independent of our criteria for classifying concordant and discordant children-in an attempt to determine whether the discordant children were more inconsistent than the concordant children when only verbal indices of consistency are considered. Thus, our indices were devised to rely on the children's spoken responses, ignoring all information contained in gesture.

Consistency between Problem Solutions and Their Explanations. We looked first at whether the strategy reflected in the solution to a given problem was consistent with the explanation for that solution. For example, if a child gave the solution ' 28 ' for the problem ' $4+6+9=$ +9 ' on the paper-andpencil test, his explanation would be considered consistent with his solution if he said, "because I added the 4, the 6, and two 9's" (i.e., the total sums to 28 ) and inconsistent if he said, "because I added 4 plus 6 plus 9" (i.e., the total sums to 19). Note that it is possible for a child to be wrong and still consistent, or wrong and inconsistent. In this study, by design, all of the children's solutions were incorrect; it was their consistency (and its relation to discordance) that was under investigation. Solution/explanation consistency was quantified in two ways: (1) using a by-response measure, that is, the number of consistent solution/explanation pairs produced by each child, and (2) using a by-child measure, that is, the number of children who produced at least 4 out of 6 consistent solution/explanation pairs.

Consistency Across Explanations. Even if a child did not produce explanations consistent with his solutions, the child still might have produced explanations that expressed a consistent strategy across six problems. Consequently, a second index of consistency was devised, based on analyses of spoken explanations independent of their associated problem solutions. Two measures of this second index were calculated: (1) a by-response measure, that is, the maximum number of explanations expressing a single strategy (either add-all, add-to-equal sign, etc.) produced by each child, and (2) a by-child measure, that is, the number of children who produced at least 4 out of 6 explanations expressing a single strategy (e.g., 4/6 explanations expressing the add-all strategy, 4/6 expressing the add-subtract strategy, etc.). 
Table 10A. Consistency Between Problem Solutions and Their Explanations

\begin{tabular}{lll}
\hline Consistency Measure & $\begin{array}{c}\text { Concordant } \\
\text { Children }\end{array}$ & $\begin{array}{c}\text { Discordant } \\
\text { Children }\end{array}$ \\
\hline $\begin{array}{l}\text { Mean number of con- } \\
\text { sistent responses } \\
\text { (out of } 6)\end{array}$ & $5.5(S D=.76)$ & $3.2(S D=1.4)^{*}$ \\
$\begin{array}{l}\text { Proportion of children } \\
\text { who had } 4 / 6 \text { consis- } \\
\text { tent responses }\end{array}$ & $94(N=32)$ & $.43(N=20)^{* *}$ \\
\hline
\end{tabular}

Table 10B. Consistency Across Verbal Explanations (independent of solutions)

\begin{tabular}{llc}
\hline Consistency Measure & $\begin{array}{c}\text { Concordant } \\
\text { Children }\end{array}$ & $\begin{array}{c}\text { Discordant } \\
\text { Children }\end{array}$ \\
\hline $\begin{array}{l}\text { Mean number of con- } \\
\text { sistent responses } \\
\text { (out of } 6)\end{array}$ & $5.5(S D=.80)$ & $3.3(S D=1.6)^{*}$ \\
$\begin{array}{l}\text { Proportion of children } \\
\text { who had } 4 / 6 \text { consis- } \\
\text { tent responses }\end{array}$ & $.94(N=32)$ & $.48(N=20)^{* *}$ \\
\hline
\end{tabular}
children.

$*_{p}<.001$, using a t-test. comparing concordant and discordant

${ }^{* *} p<.001$, using a $\chi^{2}$, comparing concordant and discordant children.

Performance of the concordant and discordant children was compared using these indices of consistency. Tables $10 \mathrm{~A}$ and $10 \mathrm{~B}$ present the data for the two consistency indices, each measured in terms of both the mean number of consistent explanations and the proportion of consistent children, for both concordant and discordant children. Concordant children achieved higher consistency scores than discordant children on both the by-child and by-response measures of the "consistency between problem solution and their explanations" index (Table $10 \mathrm{~A} ; t(50)=7.44, p<.001$, for number of explanations; $\chi^{2}(1)=22.32, p$ $<.001$, for number of children). In addition, concordant children achieved higher consistency scores than discordant children on both measures of the "consistency across verbal explanations" index (Table $10 \mathrm{~B} ; t(50)=6.44, p<$ .001 , for number of explanations; $x^{2}(1)=18.66, p<.001$, for number of children). In fact, 21 of the 32 concordant children expressed only one type of strategy in their verbal explanations while only 2 of the 20 discordant children were this consistent $\left(\chi^{2}(1)=13.27, p<.001\right)$; that is, most of the discordant children expressed at leas two different strategies in their verbal explanations while most concordant children did not. 
Since verbal inconsistency may be a characteristic of discordant children, it is reasonable to ask whether our two measures of verbal consistency can predict success after training as well as discordance can; that is, we ask whether these two verbal measures of consistency can also serve as indices of the transitional knowledge state. To address this issue, we turn to the data in our training study (Study 1) and ask (a) whether verbal inconsistency is related to discordance in this second sample of children, and (b) whether verbal inconsistency is an important factor in predicting receptivity to instruction.

\section{Discordance versus Inconsistency as Predictors of Success after Training}

We first compared the performance of the concordant and discordant children in the training study (Study 1) using the two indices of verbal consistency described above. Table 11 presents the data for the two consistency indices, each measured in terms of both the mean number of consistent explanations and the proportion of consistent children, for both concordant and discordant children. Although there is a tendency for concordant children to achieve higher consistency scores than discordant children. the differences are not significant, suggesting that verbal inconsistency does not reliably characterize the discordant child.

Table 11A. Consistency between Prohlem Solutions and their Explanations for the Children in the Training Study (Study 1)

\begin{tabular}{llc}
\hline Consistency Measure & $\begin{array}{c}\text { Concordant } \\
\text { Children }\end{array}$ & $\begin{array}{c}\text { Discordant } \\
\text { Children }\end{array}$ \\
\hline $\begin{array}{l}\text { Mean number of con- } \\
\text { sistent responses } \\
\text { (out of } 6)\end{array}$ & $4.9(S D=1.5)$ & $4.7(S D=2.0)$ \\
$\begin{array}{l}\text { Proportion of children } \\
\text { who had } 4 / 6 \text { consis- } \\
\text { tent responses }\end{array}$ & $.83(N=24)$ & $.77(N=13)$ \\
\hline
\end{tabular}

Table 11B. Consistency Across Verbal Explanations (independent of solutions) for the Children in the Training Study (Study 1)

\begin{tabular}{lll}
\hline Consistency Measure & $\begin{array}{c}\text { Concordant } \\
\text { Children }\end{array}$ & $\begin{array}{c}\text { Discordant } \\
\text { Children }\end{array}$ \\
\hline $\begin{array}{l}\text { Mean number of con- } \\
\text { sistent responses } \\
\text { (out of } 6)\end{array}$ & $5.5(S D=.71)$ & $5.1(S D=1.4)$ \\
$\begin{array}{l}\text { Proportion of children } \\
\text { who had } 4 / 6 \text { consis- } \\
\text { tent responses }\end{array}$ & $1.00(N=24)$ & $.85(N=13)$ \\
\hline
\end{tabular}


To determine whether consistency is a factor in predicting success after instruction, we calculated the proportion of children who succeeded on both the posttest and the generalization test after training as a function of each child's discordance status and consistency status on the pretest. We calculated the proportions twice-once based on each child's consistency between problem solutions and verbal explanations, and a second time in terms of the child's consistency across the set of verbal explanations. For both indices, the by-child measure was used: For the first index, a child was considered consistent if he produced four out of six verbal explanations that matched their associated problem solutions, inconsistent if he failed to do so; for the second index, a child was considered consistent if he produced four out of six verbal explanations that conveyed the same strategy, inconsistent if he failed to do so.

Table 12 presents the results for each of the two consistency indices. Although few, the inconsistent children performed like the consistent children in both the concordant and discordant groups. That is, inconsistent discordant children were as likely to improve after training as consistent discordant children, and both groups of discordant children (consistent and inconsistent) were more likely to improve than both groups of concordant children (consistent and inconsistent).

Table 12. Proportion of Children Who Improved After Training as a Function of Discordance and Consistency Status on the Pretest

\begin{tabular}{|c|c|c|}
\hline \multicolumn{3}{|c|}{$\begin{array}{c}\text { Consistency Between Problem Solutions } \\
\text { and Explanations }\end{array}$} \\
\hline \multirow{2}{*}{$\begin{array}{c}\text { Consistency } \\
\text { Status on } \\
\text { Pretest }\end{array}$} & \multicolumn{2}{|c|}{ Discordance Status on Pretest } \\
\hline & Concordant & Discordant \\
\hline $\begin{array}{l}\text { Consistent } \\
\text { Inconsistent }\end{array}$ & $\begin{array}{l}.25(N=20) \\
.25(N=4)\end{array}$ & $\begin{array}{l}.60(N=10) \\
.67(N=3)\end{array}$ \\
\hline \multicolumn{3}{|c|}{ Consistency Across Verbal Explanations } \\
\hline \multirow{2}{*}{$\begin{array}{c}\text { Consistency } \\
\text { Status on } \\
\text { Pretest } \\
\end{array}$} & \multicolumn{2}{|c|}{ Discordance Status on Pretest } \\
\hline & Concordant & Discordant \\
\hline $\begin{array}{l}\text { Consistent } \\
\text { Inconsistent }\end{array}$ & $\begin{array}{l}.25(N=24) \\
-(N=0)\end{array}$ & $\begin{array}{l}.77(N=11) \\
.50(N=2)\end{array}$ \\
\hline
\end{tabular}

"The number in parentheses is the total number of children of each type (c.g.. the total number of children who were both consistent and concordant on the pre(est); the proportion represents the number of children out of that total who succeeded on both the posttest and the generalization test. 
In sum, although there was a tendency in one of our samples of subjects for discordant children to be inconsistent in the verbal explanations they produced to justify their solutions on the paper-and-pencil test, and inconsistent in the strategies they conveyed within their set of verbal explanations, this tendency failed to appear in our second sample, suggesting that verbal inconsistency does not reliably characterize the discordant child. Moreover, neither measure of verbal inconsistency appeared to play a role in predicting success after instruction. Thus, it appears to be inconsistency in the information conveyed in speech versus gesture-rather than inconsistency in the information conveyed in speech alone-that can be used to identify children who are in transition with respect to a particular concept.

\section{DISCUSSION}

\section{Identifying Children in the Transitional Knowledge State}

Gesture has rarely been used as a tool for assessing the acquisition of concepts during development. This lack of focus on gesture may relate to the commonly held belief that gesture serves only as a precursor to specch, and that gesture wanes as speech waxes (see Jancovic, Devoe, \& Weiner, 1975). McNeill (1986) and others (e.g.. Kendon, 1980; Slamu-Cazacu, 1976) have shown that this is not so. Gesture does not disappear as speech develops; rather, gesture increases in frequency and complexity along with speech during development (Jancovic et al., 1975; McNeill, 1986) and, in fact, accompanies adult speech as frequently as child speech (McNeill, 1985). Moreover, McNeill (1986) has shown that the information conveyed in gesture ranges widely from the concrete (e.g., depicting events occurring in a cat-chases-bird cartoon) to the abstract (e.g., depicting mathematical information about the calculus of limits).

The present study provides further evidence that spontaneous gesture is not limited to a particular age group nor to a particular concept. Most of the 9through 12-year-old children in our study were found to gesture spontaneously as they explained their responses on a test of mathematical equivalence. Moreover, as in our previous study of 5- to 8-year-olds explaining their responses on a conservation test (Church \& Goldin-Meadow, 1986), many of the children in the studies reported here produced explanations in which the information conveyed in their spontaneous gestures failed to match the information conveyed in their speech.

In addition, the results of these studies confirm gesture/speech mismatch as a marker of transitional knowledge. The mismatch (discordance) between the information conveyed in gesture and the information conveyed in speech appears to index a child's readiness to make use of instruction in either mathematical equivalence or conservation (see Church \& Goldin-Meadow, 1986). Thus, gesture/speech discordance has the potential to serve as a general technique for determining the times when a child is most receptive to the environmental input, 
which stimulates change from one level of understanding of a concept to the next; that is, for determining when a child is in a transitional knowledge state with respect to a concept.

Moreover, because children produce different types of gesture/speech mismatches during these times of transition, it may be possible to use the information conveyed in mismatched responses to tailor instruction to a given child's needs. The principle-based instruction we used during the training phase of Study I was quite minimal and was identical for all children-simply telling children that the goal was to make both sides of the equation equal. Perhaps a more extensive training procedure, one which capitalizes on the implicit knowledge the discordant child displays in his gestures, might be that much more eflective in promoting learning in the discordant child.

\section{Characterizing the Transitional Knowledge State}

The transitional knowledge state has, at times, been characterized in terms of a child's level of knowledge of a concept. For example, the transitional child has been characterized as possessing a primordial version of the newly developing concept, and transitional knowledge has been described as a budding structure that is ready to bloom (Beii.i, 1965; Brainerd, 1977; Inhelder \& Sinclair, 1969: Vygotsky, 1978). A child who possesses this newly developing level of knowledge will presumably benefit from instruction because the child's cognitive structure is sufficiently advanced to accommodate sophisticated input (see Beilin, 1965: Brainerd, 1972; Langer \& Strauss, 1972; Murray, 1974; Strauss \& Langer. 1970; Strauss \& Rimalt, 1974).

An alternative attribute that has also been used to characterize the transitional knowledge state is conflict (e.g., Halford, 1970; Piaget, 1967; Siegler, 1984; Wilkinson, 1982). For example, Wilkinson (1982), in his study of children's strategies for solving problems of numerosity and density, found a subset of children who had at their disposal two incorrect algorithms which they interchanged unsystematically. As a second example, both Siegler (1984) and Piaget (1967) suggest that a subset of nonconservers will use the width dimension to solve some liquid quantity conservation problems but the height dimension to solve different liquid quantity problems. These strategies conflict in the sense that each leads to a different (incorrect) solution to the conservation problem: A child who focuses on width is likely to conclude that the low, wide dish has more water; a child who focuses on height is likely to conclude that the tall, thin glass has more water. Thus, in these characterizations, the transitional knowledge state is one in which a child simultaneously holds two conflicting beliefs about the concept. Resolution of this conflict presumably results in a more advanced understanding of the concept (Ames \& Murray, 1982; Murray, 1981, 1982; Riegel, 1975, 1976).

Our data suggest that the transitional knowledge state can be characterized by both of these factors: level of knowledge (which is indexed by whether a child's 
predominant gesture-plus-speech explanation expresses the notion of equivalence or nonequivalence), and conflict or, in our terms, stability (which is indexed by whether gesture and speech match or mismatch). For example, the child who produces primarily discordant nonequivalent explanations (Type 2) differs from the child who produces concordant nonequivalent explanations (Type 1), not in terms of the level of his knowledge (both children give rationales at the nonequivalent level), but rather in terms of the stability of that knowledge (the discordant child is more unstable than the concordant child, see Table 5). In contrast, the child who produces discordant nonequivalent explanations (Type 2) differs from the child who produces discordant mixed explanations (Type 3), not in terms of stability (both are discordant and therefore relatively unstable), but in terms of level (the child at the mixed level gives both nonequivalence and equivalence rationales; the child at the nonequivalent level gives only nonequivalence rationales). Thus, our data suggest that the transitional knowledge state is best characterized by taking into account both the level of a child's knowledge and the stability of that knowledge.

\section{The Mechanism of Transition}

We have shown that gesture/speech discordance can serve as a useful technique for the experimenter (and perhaps for the teacher as well) to identify children in transition with respect to a particular concept. We consider now whether discordance has significance for the learner himself; that is, what role (if any) does gesture/speech mismatch play in the mechanism of cognitive change? One possibility is that gesture/speech mismatch simply serves as an index of transitional knowledge and has no role whatsoever in cognitive change.

On the other hand, the production of mismatching gesture-plus-speech explanations may itself provide the impetus for change in the child's acquisition of a concept. For example, if a child recognizes (either explicitly or implicitly) that the information in his gestures conflicts with the information in the accompanying speech, that child may be compelled to reorganize his thinking to resolve the conflict. Note that our data suggest that the conflict (or inconsistency) which leads to change must appear within a single explanation rather than across a set of explanations (see Table 12). In other words, the conflicting pieces of information must be simultaneously represented in order for transition to be facilitated. Thus, this first model presumes that conflict, as made explicit at a single moment through gesture-speech mismatch, is the impetus for transition to a higher knowledge state.

A second mechanism by which gesture/speech mismatch might play a role in transition is as a "cognitive prop. " Externalizing his beliefs in two modalitiesgesture as well as speech-may help the child pull back and evaluate those beliefs, resulting in reorganization of the beliefs into a single system (see Karmiloff-Smith, 1985). Thus, it is neither the conflict, nor the gesture, per se, that leads to change; rather it is the fact that additional information is externalized 
(which presumably could occur in the form of written externalization as well as in the form of gesture) that is crucial for cognitive change. This second model presumes that a child who produces mismatches is not in a state of conflict but is in a state, where for the sake of efficiency, the numerous notions relating to a particular problem domain need to be consolidated.

Finally, gesture/speech mismatch may be important for the mechanism of change not in terms of its direct effect on the learner, but indirectly in terms of its effect on the learning environment. The match or mismatch between gesture and speech may serve as a signal to the communication partner that he should adjust his instructions accordingly. We have found in pilot work that discordant children (who produce a large proportion of gesture/speech mismatches) elicit different types of training from a naive instructor (one who has not been told to attend to gesture and its relationship to speech) than do concordant children (who produce few gesture/speech mismatches). Thus, the child may play a role in shaping his own learning environment via his production (or lack of production) of gesture/speech mismatches. This third model presumes that the child's display of instability-via his gesture-speech mismatches-alerts the environment (including teachers, parents, more advanced peers, etc.) to adjust input to the child in such a way that the child receives crucial information for conceptual reorganization.

Characterizing the mental transition that occurs when new concepts are acquired and describing the mechanisms responsible for transitions of this sort are pivotal issues in both developmental and learning research. Our work suggests that the relationship between gesture and speech may prove to be a useful tool in characterizing the stability of knowledge states and in predicting the transitions between them.

\section{REFERENCES}

Ames, G. J., \& Murray, F. B. (1982). When two wrongs make a right: Promoting cognitive change by social conflict. Devclopmental Psychology, 18, 894-897.

Baroody, A. J., \& Ginsburg, H. P. (1986). The relationship between initial meaningful and mechanical knowledge of arithmetic (pp. 75-112). In J. Hiebert (Ed.). Concepnal and procedural knowledge: The case of mathematics. Hillsdale, NJ: Erlbaum.

Beilin. H. (1965). Learning and operational convergence in logical thought development. Journal of Experimenal Child Psychology, 2, 317-339.

Blehr. M.. Erlwanger. S.. \& Nichols. E. (1980). How children view the equal sign. Mathematics Tcaching. 92, 13-15.

Brainerd, C. J. (1972). The age-stage issue in conservation acquisition. Psychonomic Science, 29. $115-117$.

Brainerd. C. J. (1973). Judgments and explanations as criteria for the presence of cognitive structures. Psychological Bulletin, 79, 172-179.

Brainerd, C. J. (1977). Cognitive development and concept learning: An integrative review. Psychological Bulletin. 84, 919-939. 
Bruwn, J. S., \& Burton, R. R. (1978). Diagnostic models for procedural bugs in basic mathematical skills. Cognirive Science, 2, 155-192.

Church. R. B., \& Goldin-Mcadow. S. (1986). The mismatch between gesture and speech as an index of transitional knowledge. Cognition, 23, 43-71.

Feldman, D. H. (1980). Beyond universals in cognitive development. Norwood. NJ: Ablex.

Feldman, H., Goldin-Meadow, S., \& Gleitman, L. (1978). Beyond Herodotus: The creation of a language by linguistically deprived deaf children. In A. Lock (Ed.). Acrion, symbol, and gesture: The emergence of language. New York: Academic.

Freeman, D. J., Kuhs, T. M., Porter, A. C., Floden, R. E., Schmidt, W. H., \& Schwille, J. R. (1983). Do textbooks and tests define a national curriculum in elementary school mathematics? Elementary School Journal. 83, 501-513.

Gelman, R. (1969). Conservation acquisition: a problem of learning to attend to relevant attributes. Journal of Experimental Child Psychology, 7, 167-186.

Ginsburg. H. (1977). Children's arithmetic, New York: Van Nostrand.

Goldin-Meadow. S. (1979). Structure in a manual communication system developed without a conventional language model: Language without a helping hand. In $\mathrm{H}$. Whitaker \& H. A. Whitaker (Eds.). Studies in neurolinguistics (Vol. 4). New York: Academic.

Goldin-Meadow, S. \& Mylander, C. (1984). Gestufal communication in deaf children: The effects and non-effects of parental input on early language development. Monographs of the Sociefy for Research in Child Development, 49 (3. Serial no. 207).

Halford, G. S. (1970). A theory of acquisition of conservation. Psychological Review. 77 (4), 302336.

Inhelder, B., \& Sinclair, H. (1969). Leaming cognitive structures. In P. H. Mussen, J. Langer, \& M. Covington (Eds.). Trends and issues in developmental psychology. New York: Holt, Rinehart \& Winston.

Jancovic, M., Devoe, S., Wiener, M. (1975). Age-related changes in hand and arm movements as nonverbal communication: some conceptualizations and empirical explorations. Child Developmen. 46. 922-928.

Karmiloff-Smith, A. (1985). Language and cognitive processes from a developmental perspective. Language and Cognitive Processes, 1, 61-85.

Keil. F. C. (1984). Mechanisms in cognitive development and the structure of knowledge. In R. J. Sternberg (Ed.), Mechanisms of cognitive development. New York: W. H. Freeman.

Kendon. A. (1980). Gesticulation and speech: two aspects of the process of utterance. In M. R. Key (Ed.). Relationship of the verbal and nonverbal communication. The Hague: Mouton.

Kessen, W. (1962). "Stage" and "structure" in the study of children. Cognitive development in children. Monographs of the Sociery for Research in Child Development. 27(2), 65-86.

Kessen. W. (1984). Introduction: The end of the age of development. In R. J. Sternberg (Ed.). Mechanisms of cognitive development. New York: W. H. Freeman.

Kieran, C. (1980). The interpretation of the equal sign: Symbol for an equivalence relation vs. an operator symbol. Proceedings of the Fourth International Conference for the Psychology of Mathematics Education. 163-169.

Langer. J., \& Strauss, S. (1972). Appearance, reality and identity. Cognition, /(1), 105-128.

Mayer, R. E., \& Greeno, J. G. (1972). Structural differences between learning outcomes produced by different instructional methods. Journal of Educational Psychology. 63, 165-173.

McNeill. D. (1985). So think gestures are nonverbal? Psychological Review, 92.(3), 350-37!.

McNeill, D. (1986). Iconic gestures of children and adults. Semionica, 62, 107-128.

McNeill. D., \& Levy. E. (1982). Conceptual representations in language activity and gesture. In R. J. Jaravella \& W. Klein (Eds.), Speech, place and action. New York: Wilcy.

Murray. J. P. (1974). Social learning and cognitive development: modelling effects on children's understunding of conservation. British Journal of Psychology, 6S, (1), 151-160. 
Murray, F. B. (1981). The conservation paradigm: The conservation of conservation research. In D. Brodzinsky. 1. Sigel, \& R. Golinkoff (Eds.). New directions in Piagetian theory and research. Hillsdale, NJ: Erlbaum, 142-175.

Murray. F. B. (1982). Teaching through social conflict. Contemporarv Educational Psvchology, 7. 257-271.

Perry. M. (1985. April). Children's strategies in interpreting symbolic equivalence. Paper presented at the biennial meeting of the Society for Research in Child Development, Toronto, Canada.

Perry, M.(1988a). Problem assignment and learning outcomes in nine fourth-grade mathematics classes. Elementary School Journal. 88, 413-420.

Perry. M.(1988b). Knowledge in transition: The role of instruction. Manuscript submitted for publication.

Perry. M.. Church. R. B., \& Goldin-Meadow. S. (1988, April). Leaming a principle vs. learning a procedure: Looking beyond what is taught. Paper presented at the annual meeting of the American Educational Research Association. New Orleans, LA.

Piaget. J. (1967). Six psychological studies. New York: Random House.

Riegel, K. F. (1975). Adult life crises: Toward a dialectic theory of development. In N. Datan \& L. H. Ginsberg (Eds.), Life-span developmental psychology: Normative life crises. New York: Academic.

Riegel, K. F. (1976). The dialectics of human development. American Psychologist, 31, 689-700.

Siegler, R. S. (1976). Three aspects of cognitive development. Cognitive Psychology, 8. 481-520.

Siegler, R. S. (1979). The origins of scientific reasoning. In R. S. Siegler (Ed.), Children's thinking: What develops" Hillsdale, NJ: Erlbaum.

Siegler, R. S. (1981). Developmental sequences within and between concepts. Monographs of the Society for Research in Child Development, 46 (2, Serial no. 189).

Siegler, R. S. (1984). Mechanisms of cognitive growth: Variation and selection. In R. J. Stemberg (Ed.), Mechanisms of cognitive development. New York: W. H. Freeman.

Slamu-Cazacu. T. (1976). Nonverbal components in message sequence: "Mixed syntax. " In W. C. McCormack \& S. A. Wurm (Eds.), Language in man: Anthropological issues. The Hague: Mouton.

Sternberg. R. J. (1984). Mechanisms of cognitive development. New York: Freeman.

Strauss. S. (1972). Inducing cognitive development and learning: A review of short-term training experiments. I. The organismic developmental approach. Cognition, 1, 329-357.

Strauss, S., \& Langer, J. (1970). Operational thought inducement. Child Development, 40, $163-$ 175.

Strauss, S., \& Rimalt, I. (1974). Effects of organizational disequilibrium training on structural elaboration. Developmental Psychology, 10. 526-533.

Vygotsky, L. S. (1962). Thought and language. Cambridge, MA: M.I.T. Press.

Vygotsky, L. S. (1978). Mind in society. Cambridge, MA: Harvard University Press.

Wagner, R. K., \& Torgesen, J. K. (1987). The nature of phonological processing and its causal role in the acquisition of reading skills. Psychological Bulletin, 101, 192-212.

Wilkinson. A. C. (1982). Partial knowledge and self-correction: Developmental studies of a quantitative concept. Developmental Psychology, 18, 874-891. 